\title{
Rhodococcus equi peritonitis in continuous ambulatory peritoneal dialysis: a first in Australia
}

\author{
Omar Azzam, ${ }_{1}^{1}$ Amy Crowe, ${ }^{2}$ Cherian Sajiv, ${ }^{3}$ Basant Pawar ${ }^{1}$
}

${ }^{1}$ Department of Nephrology, Alice Springs Hospital, Alice Springs, Northern Territory, Australia

${ }^{2}$ Department of Microbiology, Royal Darwin Hospital, Alice Springs, Northern Territory, Australia

${ }^{3}$ Alice Springs Hospital, Alice Springs, Northern Territory, Australia

Correspondence to Dr Omar Azzam, omarazzam@hotmail.com

Accepted 16 September 2015

\section{SUMMARY}

A 33-year-old Caucasian man with end-stage renal disease secondary to biopsy-proven IgA nephropathy, managed with continuous ambulatory peritoneal dialysis (PD), presented with PD-related peritonitis, the causal organism being a non-branching Gram-positive bacillus, Rhodococcus equi. Initial empirical Gram positive and negative coverage with cefazolin and ceftazidime was unsuccessful, but following isolation of the organism, and conversion to intraperitoneal vancomycin and oral ciprofloxacin, the peritonitis episode resolved. At day 10, vancomycin was switched to azithromycin for a total of 6 weeks of antimicrobial therapy. The PD catheter was preserved, and the patient remained peritonitis-free at 6 months of follow-up.

\section{BACKGROUND}

Our case highlights the potential for success in managing peritoneal dialysis (PD) peritonitis secondary to a rather uncommon and variably antibiotic-responsive organism. The delay in isolating Rhodococcus equi risks concluding treatment failure, which would eventuate in removal of the catheter and conversion, as per the widely implemented International Society for Peritoneal Dialysis (ISPD) peritonitis guidelines. Prolonged therapy with antimicrobials has demonstrated varying rates of success in the few reported cases to date, and has achieved the desired outcome of catheter preservation and continuation of the patient's preferred mode of renal replacement.

\section{CASE PRESENTATION}

A 33-year-old Caucasian man with end-stage renal disease secondary to biopsy-proven IgA nephropathy had a PD catheter surgically inserted in January 2012, and PD started in October 2012. He was initiated on automated PD (APD), and later converted to continuous ambulatory PD (CAPD) while on his work-related travels through the Northern Territory of Australia. A peritoneal equilibrium test (PET) 3 months into PD therapy demonstrated high-average transporter membrane characteristics. The patient presented to our regional hospital in August 2013, with a 1-day history of mild generalised abdominal pain and tenderness, accompanied by cloudiness of the dialysis effluent. This followed handling of farming machinery a few days preceding his presentation to hospital. He denied direct contact with horses or other farm animals during his work-related journey.

The initial dialysate white cell count (WCC) was $3960 \mathrm{cells} / \mathrm{mm}^{3} \quad(91 \%$ polymorphs $)$ and no organisms were identified on Gram stain. Empirical intraperitoneal (IP) antibiotics were started (cefazolin $1 \mathrm{~g}$ daily and ceftazidime $1 \mathrm{~g}$ daily) as per the International Society of Peritoneal Dialysis guidelines and the local PD peritonitis therapeutic protocol. Aerobic and anaerobic cultures did not yield any organisms after $48 \mathrm{~h}$. There was a partial initial response to treatment, with the WCC dropping to 1190 cells $/ \mathrm{mm}^{3}$ by day 3 , followed by a clear appearance of the dialysate on day 4 , and a significant drop in dialysate WCC to 130 cells $/ \mathrm{mm}^{3}$ on day 7 .

On day 3, the enrichment broth turned positive for non-branching Gram-positive bacilli. The enrichment broth was subcultured onto horse blood agar, and after $24 \mathrm{~h}$ incubation in $5 \% \mathrm{CO}_{2}$, revealed growth of non-haemolytic pink-pigmented colonies. The isolate was a strict aerobe, oxidase positive, and failed to grow on MacConkey agar. It was identified by a commercial API kit and Mass Absorption Laser Depolarising Ionisation time-of-flight (MALDI-tof) as R. equi. No in vitro sensitivity testing was conducted at the Central Microbiology Laboratory at Royal Darwin Hospital, Northern Territory.

As a result, we switched the antimicrobial regime to IP vancomycin (1 g repeated every $72 \mathrm{~h}$ ) and oral ciprofloxacin $500 \mathrm{mg}$ once daily. This was based on extrapolation from successes reported with the use of IP vancomycin. This did not achieve normalisation of the dialysate WCC, which remained greater than $100 \mathrm{cells} / \mathrm{mm}^{3}$ after 5 days of treatment with this combination. At this juncture, the decision was to proceed with PD catheter removal and conversion to haemodialysis, but the patient made an informed decision to persevere with $\mathrm{PD}$, and elected to transfer his care to a tertiary centre. IP vancomycin and oral ciprofloxacin were continued for a further 5 days, and after a total of 10 days with this combination, the WCC declined to $<100 \mathrm{cells} / \mathrm{mm}^{3}$ and the effluent cleared on direct visual examination. Vancomycin was switched to oral azithromycin, alongside ongoing ciprofloxacin, and this combination was continued for a further 6 weeks. There were no further episodes of peritonitis on completion of therapy, and the patient remained infection-free on surveillance testing at 3 and 6 months following this episode. A follow-up PET study at 6 months showed that he remained a high-average transporter in spite of this episode of peritonitis.

\section{DISCUSSION}

$R$. equi is a well-described cause of pneumonia in horses and immunocompromised humans. ${ }^{1}$ 
There has been variable success in treatment of $R$. equi infections, both pulmonary and extrapulmonary, in individuals infected with HIV. The introduction of highly active antiretroviral therapy (HAART) is a major contributor to improved survival with this infection, prior to which the disease was fatal in up to $80 \%$ of cases. ${ }^{2}$ The first reported case of R. equi infection in humans was in $1967 .{ }^{3}$ Since then, there have been infrequent case reports of Rhodococcus spp infections, predominantly in immunocompromised hosts, namely, those with HIV infection, ${ }^{4}{ }^{5}$ and in transplant recipients. ${ }^{6}$ The most common site for Rhodococcus spp infection is pulmonary, where it can manifest as a cavitating pneumonia. ${ }^{7}$

There are very few case reports and case series of Rhodococcus spp peritonitis, most being encountered in Hong Kong. ${ }^{8}{ }^{9}$ The presumption is that direct inoculation through contact contamination of the PD catheter leads to this highly treatment-refractory infection. $R$. equi's virulence and resistance to most antimicrobial agents is likely attributable to its mycobacteria-like behaviour, being able to persist within, and destroying macrophages. ${ }^{1}$

$R$. equi is a soil organism carried in the gut of many herbivores and widespread in their environment. The patient denied direct contact with livestock, but reported that he engaged in maintenance and repair of farming machinery in the week preceding his presentation to our service, and did admit to likely contact contamination while carrying out his PD exchanges in a mobile setting.

The incomplete response to the initial ISPD guidelines-based antimicrobial regime by day 5 of treatment would, in general principle, lead to removal of the PD catheter in an effort to reduce patient morbidity and preserve the peritoneal membrane. The effluent culture results were received on day 6 of therapy, at which time there was serious consideration for catheter removal, but a review of the published literature presented us with the prospects of successful treatment, while preserving the catheter. Switching the antimicrobial regime to IP vancomycin in combination with oral ciprofloxacin did, albeit not until day 10 , eventuate in clearance of the dialysis effluent. This favourable response was consolidated with conversion of vancomycin to azithromycin in addition to ongoing ciprofloxacin for a further 6 weeks.

There is a single case report of a short-lived response to approaches using azithromycin alone or in combination, but the outcome was uniformly that of eventual catheter removal. ${ }^{10}$ The catheter was salvaged in four of the six cases of $R$. equi peritonitis in the series reported by Chow et al. ${ }^{8}$ This was achieved in three of the five cases in which intraperitoneal vancomycin was employed as an initial and/or a salvage agent. ${ }^{3}$ A desirable outcome was also achieved in separately reported cases in which vancomycin was used. ${ }^{911}$ Treatment went on for a minimum of 21 days in all but one of these case reports. The previous single successful experience treatment with IP imipenem and cilastatin was not replicated in the Chow et al case series.

This case, as others previously reported in the literature have, highlights several management challenges posed by Rhodococcus spp PD-related peritonitis. The most effective antimicrobial regime continues to elude us due to limited experience in treating this type of infection. Although there have been cases where the infection was adequately treated without removal of the PD catheter, the desire to preserve peritoneal membrane integrity precludes protracted antimicrobial ventures.

On balance, given the rather unpredictable response to therapy, and considering standard recommendations made by the ISPD guidelines, the default course of action is removal of the PD catheter in the event of refractory peritonitis defined as failure of the effluent to clear after 5 days of appropriate antibiotics. ${ }^{12}$ However, successful treatment in this case and others presents us with the possibility of successful PD-salvaging treatment using prolonged courses of antibiotics while being mindful of the potential for both increased morbidity and compromise of future re-institution of PD in the event of delayed clearance of the infection.

\section{Learning points}

- Rhodococcus equi is a rare cause of PD peritonitis.

- Response to antibiotics is highly variable and, in many instances, infection with this organism leads to loss of the PD catheter.

- The treatment-refractory nature of $R$. equi infection likely relates to its microbiological characteristics coupled with impaired host immunity in patients with end-stage renal disease.

- There is potential for successful treatment with prolonged courses of combinations of vancomycin, azithromycin and ciprofloxacin, while preserving the PD catheter, but this must be weighed against the risk of infection-related morbidity and detrimental long-term effects to the peritoneal membrane.

Contributors OA managed the case presented in this submission, reviewed the literature relating to the topic and prepared the manuscript. AC contributed the microbiological component of the manuscript. BP and CS proofread and made contributions to this case report.

Competing interests None declared.

Patient consent Obtained.

Provenance and peer review Not commissioned; externally peer reviewed.

\section{REFERENCES}

1 Prescott JF. Rhodococcus equi: an animal and human pathogen. Clin Microbiol Rev 1991;4:20-34.

2 Torres-Tortosa M, Arrizabalaga J, Villanueva JL, et al. Prognosis and clinical evaluation of infection caused by Rhodococcus equi in HIV-infected patients: a multicenter study of 67 cases. Chest 2003;123:1970.

3 Golub B, Falk G, Spink WW. Lung abscess due to Corynebacterium equi. Report of first human infection. Ann Intern Med 1967;66:1174-7.

4 Drancourt M, Bonnet $\mathrm{E}$, Gallais $\mathrm{H}$, et al. Rhodococcus equi infection in patients with AIDS. J Infect 1992;24:123-31.

5 Donisi A, Suardi MG, Casari S, et al. Rhodococcus equi infection in HIV-infected patients. AIDS 1996;10:359-62.

6 Cronin SM, Abidi MH, Shearer CJ, et al. Rhodococcus equi lung infection in an allogeneic hematopoietic stem cell transplant recipient. Transpl Infect Dis 2008; 10:48-51.

7 Verville TD, Huycke MM, Greenfield RA, et al. Rhodococcus equi infections of humans. 12 cases and a review of the literature. Medicine (Baltimore) 1994;73:119-32.

8 Chow KM, Szeto CC, Chow VC, et al. Rhodococcus equi peritonitis in continuous ambulatory peritoneal dialysis. J Nephrol 2003;16:736-9.

9 Tang S, Lo CY, Lo WK, et al. Rhodococcus peritonitis in continuous ambulatory peritoneal dialysis. Nephrol Dial Transplant 1996;11:201.

10 Hoque $S$, Weir $A$, Fluck $R$, et al. Rhodococcus equi in CAPD-associated peritonitis treated with azithromycin. Nephrol Dial Transplant 1996;11:2340-1.

11 Brown E, Hendler E. Rhodococcus peritonitis in a patient treated with peritoneal dialysis. Am J Kidney Dis 1989;14:417-18.

12 Li PK, Szeto CC, Piraino B et al., International Society for Peritoneal Dialysis. Peritoneal dialysis-related infections recommendations: 2010 update. Perit Dial Int 2010;30:393-423. 
Copyright 2015 BMJ Publishing Group. All rights reserved. For permission to reuse any of this content visit http://group.bmj.com/group/rights-licensing/permissions.

BMJ Case Report Fellows may re-use this article for personal use and teaching without any further permission.

Become a Fellow of BMJ Case Reports today and you can:

- Submit as many cases as you like

- Enjoy fast sympathetic peer review and rapid publication of accepted articles

- Access all the published articles

- Re-use any of the published material for personal use and teaching without further permission

For information on Institutional Fellowships contact consortiasales@bmjgroup.com

Visit casereports.bmj.com for more articles like this and to become a Fellow 